\title{
Effect of Combined Refining Plates with Different Bar Angles on Paper Properties during Mixed Pulp Refining ${ }^{1}$
}

\author{
Xiya GUOD $\mathbb{D}^{2,3,4, \dagger} \cdot$ Jixian DONG $\mathbb{D}^{2,3, \dagger} \cdot$ Huan $\mathrm{LIU}^{2,3} \cdot$ Chuanwu DUAN ${ }^{2,3} \cdot$ \\ Ruifan $\mathrm{YANG}^{2,3} \cdot \mathrm{Kai} \mathrm{QI}^{2,3}$
}

\begin{abstract}
Pulp refining is the major way to alter the properties of fibers and formed paper. Different combinations of the bar profile of the rotor and stator during low consistency refining processes directly affect the properties of the paper. In this study, a mixture of softwood and hardwood pulp was refined by varying the bar angle of the stator while that of the rotor is fixed at $0^{\circ}$. The pulp samples were collected at different refining times. Then, the pulp and paper properties, such as beating degree, fiber external fibrillation, and tensile and tear indexes were measured to explore the effects of the combined refining plates at different bar angles on paper properties. The results of the experiment show that the combined refining plate of $0^{\circ}$ and $5^{\circ}$ recorded the most significant improvement in the pulp beating degree and fiber external fibrillation. This consequently increased the fiber bonding area, which in turn, improved both the tensile and the tear indexes of the paper. Also, the influence of the combined refining plates with a larger bar angle on the paper properties was weaker compared to that of smaller angles. This study not only provides ideas for the bar profile design but also improves the optimal selection of refining plates.
\end{abstract}

Keywords: disc refiner, combined refining plate, bar angle, fiber and paper properties, mixed pulp

\section{INTRODUCTION}

Paper is a type of sheet-like material with structure of porous network, and it is interwoven with fibers and other solid particles. Its properties is mainly determined by the pulp and fiber properties, and there is a significant effect of it on the microstructure of formed paper. The pulp refining is an important process for modifying the properties of pulp and fibers, and the objective of it is to fully develop the fiber and pulp properties to meet specific requirements of paper used in different situations (Zhang and Xia, 2014).

Refining, as the main way to change the fiber and pulp performance, is the process of changing the phys-

${ }^{1}$ Date Received March 12, 2020, Date Accepted June 29, 2020

2 College of Mechanical and Electrical Engineering, Shaanxi University of Science \& Technology, Xi'an, Shaanxi Province, 710021, People's Republic of China

${ }^{3}$ China Key Laboratory of Light Industry Equipment Manufacturing Intelligence, Xi'an, Shaanxi Province, 710021, People's Republic of China

${ }^{4}$ College of Art and Design, Shaanxi University of Science \& Technology, Xi'an, Shaanxi Province, 710021, People's Republic of China

† Corresponding author: Xiya GUO (e-mail: guoxiyaya@163.com, ORCID: 0000-0002-5844-5200) and Jixian DONG (e-mail: djx@sust.edu.cn, ORCID: 0000-0002-2373-2525) 
ical characteristics of the fiber and adjusting the specific surface area of the fiber by using shearing and compression forces produced by different refining elements (Shi and He, 2008). The main refining equipments include disc refiners and conical refiners (Zhang and Xia, 2014 ), and the disc refiner is widely used one due to its good refining performance, stable pulp quality and various bar structures, which can easily meet the refining requirements of different papers (Guo et al., 2019).

The refining plate is the core part of the disc refiner, and the refining energy transmitted to the wood chips and fibers are mostly determined by the bar profile. Therefore, the design and selection of the refining plate have a direct impact on the quality of pulp and fibers (Li, 2002; Chi et al, 2015). The refining quality, power consumption and paper properties can be optimized by adjusting bar width, groove width, bar height and bar angle of the refining segments (Chi et al, 2015; Yang and Jiang, 2010; Elahimehr, 2014). Liu et al. (2019) pointed out that specific edge load (SEL) was not an effective indicator to characterize the refining characteristics of isometric straight bar plate with different bar angles in low consistency refining, and the smaller the bar angles were, the stronger the fiber cutting was. Vomhoff (1990) studied the influence of the plate bar angle on the refining quality and efficiency, and the total intersecting area, the number of bar crossing points and total length of cutting edges were analyzed by simulating the passing process of rotor over the stator. Siewert and Selder, Brecht et al., Pfaffli. (1980; 1965; 2015) found that there is a significant effect of bar angles on the refining results under the same refining conditions. In addition, some scholars analyzed the effects of combined refining plates with different bar angles on the refining characteristics. Hammar et al. (2010) found that the energy consumption and pulp quality can be changed by optimization of refining process considering the mechanical pulp refining conducted by conical refiner equipped by combined refining plates with different bar angles. Roux et al. (2009) performed refining experiments with combined refining plates of different bar angles, and found that the SEL could not accurately explain the effect of refining on fiber properties due to the less consideration of bar angle, which is consistent with the conclusion of Liu et al. (2019).

Except for the bar profile of the refining plate, the refining methods also have different effects on the properties of the pulp and paper. Chauhan et al. (2011) found that the properties of paper made by a mixed pulp, which is mixed by softwood and hardwood pulp, before refining was better than that of paper made by the mixed pulp, which is refining separately and then mixed. Wu et al. (2004) found that the excessive cutting of short fiber can be avoided through mixed pulp refining, and it was also a compromise method to maintain fiber strength characteristics, and increase the light scattering coefficient of the paper, when studying the mixed pulp refining of birch and black spruce pulp. Kasmani et al. (2013) found that the fiber internal bonding force, the density and tensile strength of paper could be significantly improved due to the increasing of fiber fibrillation duringthe mixed refining of softwood and hardwood pulp.

At present, there are few studies that exploring the influence of bar angle and combined refining plates on the paper properties, and most of them focus on the influence of the bar angle on pulp properties and energy consumption. In this study, softwood and hardwood mixed pulp was refined by combined refining plates with different bar angles. And the pulp and fiber properties (pulp beating degree and fiber external fibrillation) of pulp samples, and paper properties (the bulk, tensile and tear index, and the micro morphology) of the handsheets were analyzed to clarifythe effects of the combined plates with different bar angles on paper properties. 
Effect of Combined Refining Plates with Different Bar Angles on Paper Properties during Mixed Pulp Refining

Table 1. Details of fiber raw materials used in refining

\begin{tabular}{cccc}
\hline Pulp & Fiber length $(\mathrm{mm})$ & Fines content $(\%)$ & Beating degree ( ${ }^{\circ}$ SR) \\
\hline \hline Bleached hardwood pulp & $0.65 \sim 0.85$ & 8.0 & 13 \\
Unbleached softwood pulp & $2.00 \sim 3.00$ & 7.5 & 13 \\
\hline
\end{tabular}

\section{MATERIALS and METHODS}

\subsection{Fiber raw materials}

In this study, mixed pulp of bleached hardwood pulp and unbleached softwood pulp was used in the ratio of four to one, and it was soaked in water for $4 \mathrm{~h}$ before refining. The detail of the pulp properties are shown in Table 1.

\subsection{Refining}

The consistency of the mixed pulp was adjusted to $3 \%$ before refining, and MD3000 laboratory disc refiner (Regmed, Osasco, Brazil) was used for refining, as shown in Fig. 1. The refining was conducted by using four combined refining plates with different bar angles at a constant speed of $1460 \mathrm{rpm}$. The bar profiles of them are shown in Table 2 and 3. The straight bar plate with bar angle of $0^{\circ}$ was fixed as the rotor, and different combinations of refining plates were achieved by changing the refining plates (stator) with different bar angles, such as $0^{\circ}, 5^{\circ}, 22^{\circ}$ and $50^{\circ}$. Among them, the combined refining plate with different stator

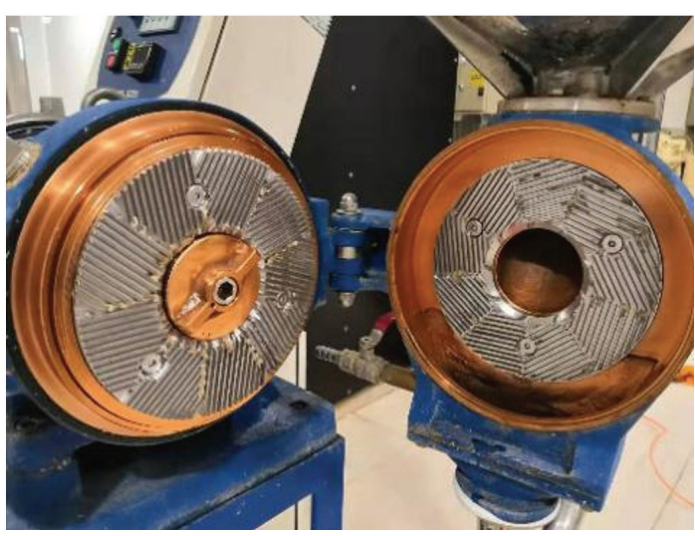

Fig. 1. The MD3000 SD refiner.

Table 2. The bar parameters of four stator plates

$\begin{array}{ccccccccc}\text { Disc } 1 & \text { Disc } 2 & \text { Disc } 3 \\ \text { Refining plate } \\ \text { of stator }\end{array}$

Table 3. Common bar parameters of all plates

\begin{tabular}{ccccccc}
\hline $\begin{array}{c}\text { Bar angle of } \\
\text { rotor }\end{array}$ & Bar width & Groove width & Bar height & Inner diameter & Outer diameter & field angle \\
\hline \hline $0^{\circ}$ & $2 \mathrm{~mm}$ & $3 \mathrm{~mm}$ & $4 \mathrm{~mm}$ & $82.5 \mathrm{~mm}$ & $203 \mathrm{~mm}$ & $40^{\circ}$ \\
\hline
\end{tabular}


bar angles were regarded as Disc 1, Disc 2, Disc 3, and Disc 4. All plates were directly custom made by Nantong Huayan Casting Co., Ltd. (Nantong, China) through a Computer Numerical Control machine tool (CNC) (Shenzhen Dima Co., Ltd., Shenzhen, China).

In the refining process, the soaked pulp was disintegrated at a gap of $5 \mathrm{~mm}$ for 4 minutes, and then the pulp sample 1 was gained when the pulp was refined for 4 minutes after the gap was adjusted to 2 $\mathrm{mm}$. After that, the gap clearance was adjusted to 0.1 mm quickly, and then 10 pulp samples were collected at 2-minute intervals. The samples collected at different times were centrifuged and dried by an electric blast drying oven 101 (Beijing Zhongxing Weiye Instrument Co., Ltd., Beijing, China) to calculate the pulp moisture for subsequent experiments.

\subsection{Measurement of fiber, pulp and paper properties}

The beating degree of the pulp samples was measured with Schopper-Riegler ( $\left.{ }^{\circ} \mathrm{SR}\right)$ tester as per ISO 5267-1:1999 method (1999), morphology of formed papers at different time was observed by Scanning Electron Microscopy (SEM), and the fiber fibrillation was analyzed by fiber quality analyzer (FS5, Valmet, Espoo, Finland). Handsheets were made by Lab Handsheet Former based on ISO 5269-1:2005 (2005). And their physical properties, including bulk, tensile and tear strength,were measured based on TAPPI T220 (2001) using a tensile strength meter 062 (L\&W, Kista, Sweden) and a paper tear strength meter (SLY-S1; Labthink, Jinan, China).

\section{RESULTS and DISCUSSION}

\subsection{Beating degree}

Beating degree is one of the main indicators of pulp draining performance, which can comprehensively re- flect the degree of fiber cutting, swelling and fiber fibrillation, and it is easily affected by temperature and consistency (Shi and He, 2008). Therefore, the laboratory temperature was maintained at about $20^{\circ} \mathrm{C}$ during the experiments, and the pulp consistency was controlled at $0.2 \%$. In this paper, the change of beating degree of mixed pulp refined by four combined plates was explored, as shown in Fig. 2. It was found that the impact of the four refining plates on the pulp beating degree was obvious, but the changing trend of them was different over refining time. The beating degree of pulp samples refined by Disc 2 until ten minutes increased fastest among 4 trials, and Disc 1 promoted the beating degree faster compared to that of the Disc 3 and 4, while Disc 4 was the slowest on the change ability of beating degree. The increase of the beating degree of pulp samples refined by the Disc 1 and Disc 2 slowed down when the refining time is longer than 14 minutes, however, the beating degree of pulp samples refined Disc 3 and 4 continuously increased due to the poor ability of beating degree improvement.

\subsection{Fibers external fibrillation}

Fibrillation refers to the phenomenon that fibers was split longitudinally and the fines fibers was separated out which is still in touch with the fiber surface due to the mechanical and physical effects of the refiner. Fiber fibrillation can be divided into external fibrillation and internal fibrillation. The increase of fiber external fibrillation can not only strengthen the fiber bonding force, but also improve the strength of formed paper, such as tensile and tear strength (Liu, 2008; He, 2010; Strachan, 1938; Kang, 2007; Clark, 1969; Jayme and Hunger, 1957). In this study, it was measured by fiber quality analyzer indicating the projection area of the fibrils in relation to the projection area of the entire object, scaled into a percentage. The fiber external 


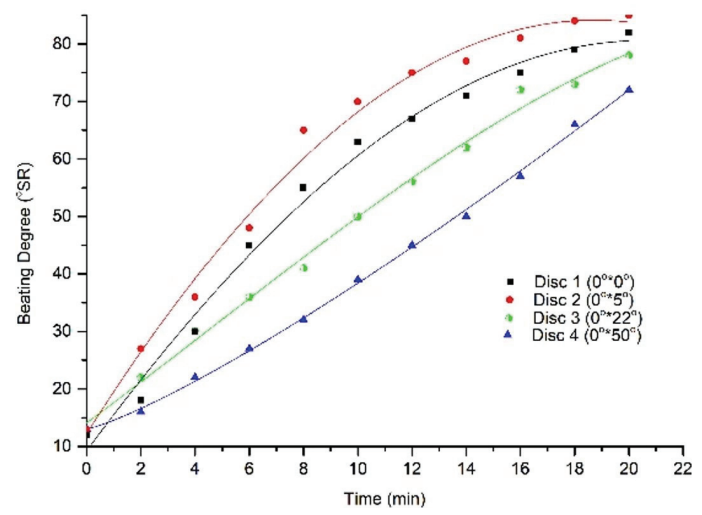

Fig. 2. The beating degree changes of samples refined by four combined plates over the refining time.

fibrillation of pulp samples refined by the four combined refining plates were analyzed, and there was a difference in the external fibrillation changes of the pulp samples refined by them, as shown in Fig. 3. The fiber external fibrillation of the pulp samples was enhanced with the progress of the refining, while the change ability on fiber external fibrillation of Disc 2 is strongest, which increased the fiber external fibrillation from $6.32 \%$ to $15.09 \%$, with a change rate of $0.439 \%$ over time. And the change rates of fiber external fibrillation for Disc 1, Disc 3, and Disc 4 over time were $0.377 \%, 0.352 \%$ and $0.267 \%$ respectively. Therefore, it can be concluded that Disc 2 can improve the fiber external fibrillation obviously. It was found that the fiber strength and paper properties were sensitive to changes in the fiber external fibrillation, which means the paper strength will change significantly even if the change in the fiber external fibrillation is small (He, 2010). The fiber external fibrillation can also be reflected by the fiber morphology of formed paper, and the combination of the external fibrillation and fiber morphology can more effectively explain the refining effect of the four combined refining plates. The fiber morphology of formed paper made by the pulp samples refined for 6 minutes and 20 minutes

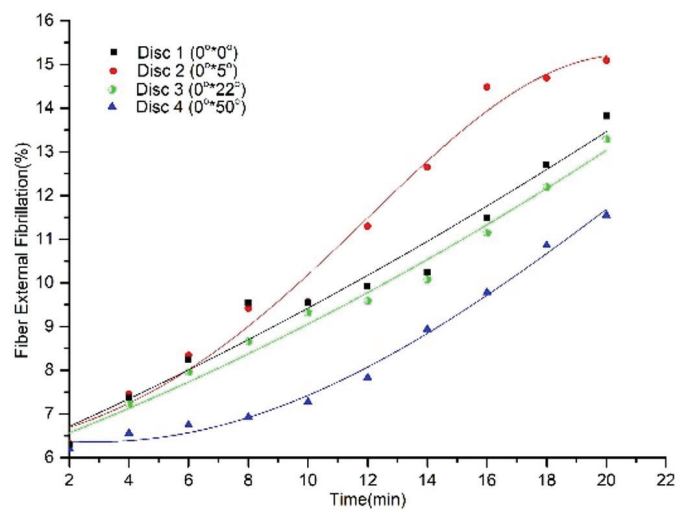

Fig. 3. The fiber external fibrillation of pulp samples refined by four combined plates over the refining time.

were analyzed, as shown in Fig. 4 and 5. It was shown that the type of fiber external fibrillation was different refined by different combined refining plates after 6 minutes, as shown in Fig. 4. The external fibrillation of the fibers became fluffy and "hair-like" fibrils when the pulp was refined by Disc 1, 2 and 3, while the fluffing and "hair-like" fibrils in Fig. 4(d) were not obvious, which meant less fiber external fibrillation and was consistent with the results shown in Fig. 3.

The fiber morphology of formed paper made by pulp samples refined by four combined refining plates after 20 minutes was shown in Fig. 5. It can be found that most of "hair-like" (indicated by yellow arrows), thin thread-like (indicated by white arrows) and lamellar sheets fibrils (indicated by red arrows) types of fiber external fibrillation were existed in Fig. 5(b), which indicated the change ability in external fibrillation of Disc 2 was the strongest. The three types of fibrils mentioned above was found in the formed paper made by pulp refined by Disc 1 , as shown in Fig. 5(a). While the content of them in the formed paper made by pulp refined by Disc 4 were the least, as shown in Fig. 5(d), which indicates that the change ability in external fibrillation of it was the weakest among them. This conclusion drawn here was exactly 


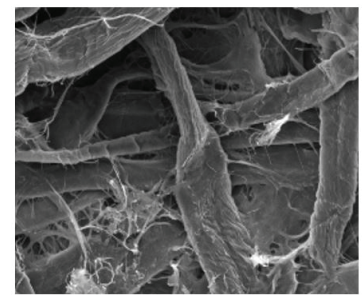

(a)

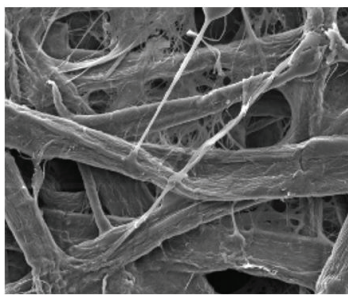

(b)

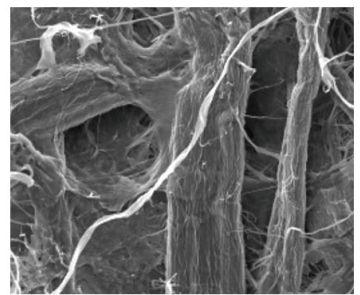

(c)

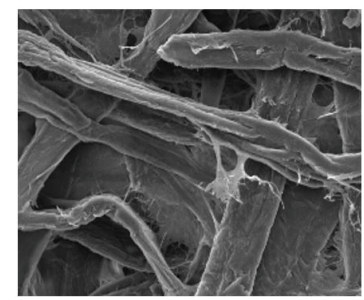

(d)

Fig. 4. Morphology of fibers (2kx) with Disc 1(a), Disc 2(b), Disc 3(c) and Disc 4(d) after refining for 6 min.

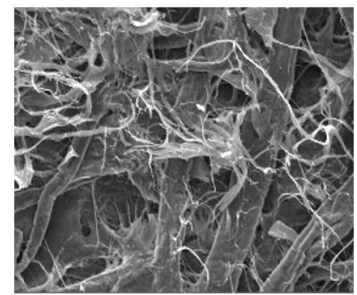

(a)

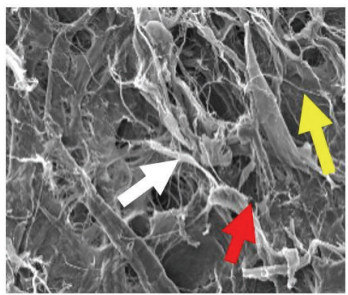

(b)

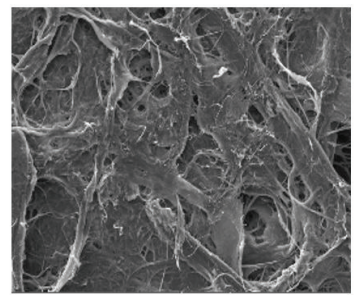

(c)

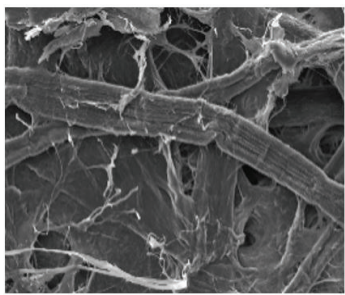

(d)

Fig. 5. Morphology of fibers (2kx) with Disc 1(a), Disc 2(b), Disc 3(c) and Disc 4(d) after refining for 20 min.

the same as that of the analysis in Fig. 3. The relative bonding area of thin thread-like and lamellar sheets fibrils was relatively large, and more thin thread-like and lamellar sheets fibrils provided more possibilities for hydrogen bonding between fibers, which could increase the strength of paper (Fernando et al., 2014). Therefore, it can be concluded that the fibers refined by the combined refining with a smaller bar angle were more likely to produce external fibrillation, increase the specific surface area of the fibers.

\subsection{Physical properties of paper}

Bulk is one of main properties of paper, which refers to the volume of paper of a certain mass, andis related to factors such as types of fibers and the beating degree (Shi and He, 2008). Paper with high bulk can maintain the necessary stiffness, and can save the pulp consumption to specific area of paper. However, paper with low bulk shows higher tightness (Peng and Liu, 2014). The bulk of the handsheets made by pulp samples refined by four combined refining plates were shown in Fig. 6. The bulk of the handsheets made by pulp samples refined by Disc 2 decreased linearly from $1.99 \mathrm{~cm}^{3} / \mathrm{g}$ to $1.512 \mathrm{~cm}^{3} / \mathrm{g}$ with the increasing of refining time, while Disc 4 gradually reduced the bulk of paper from $2.508 \mathrm{~cm}^{3} / \mathrm{g}$ to $1.781 \mathrm{~cm}^{3} / \mathrm{g}$. In other words, the tightness of the formed paper made by

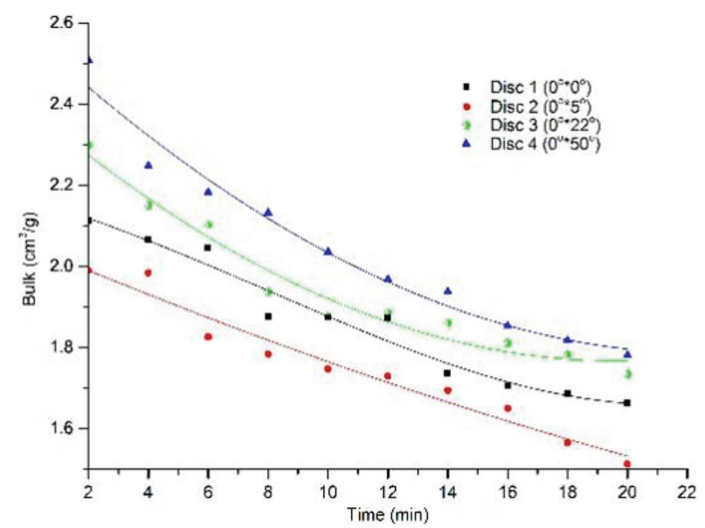

Fig. 6. Bulk of handsheets made by pulp refined by four combined refining plates. 


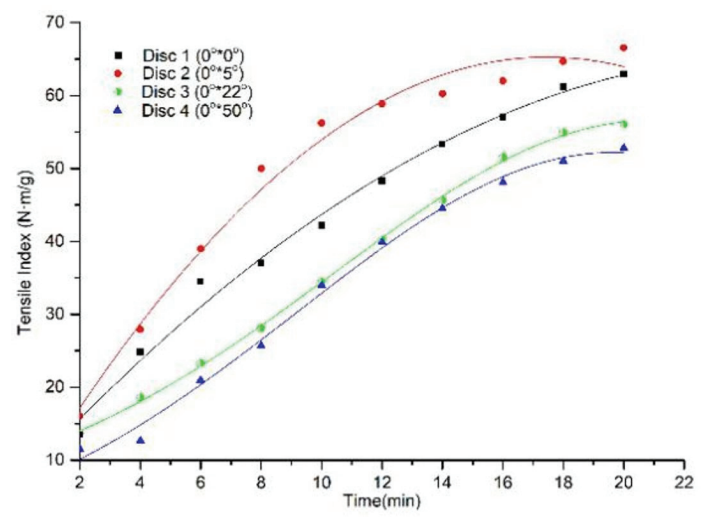

Fig. 7. Variation of the tensile index of paper made by the four combined refining plates.

pulp samples refined by combined refining plate with a smaller bar angle was higher, while the bulk of the formed paper made by pulp refined by a combined refining plate with a larger bar angle was higher.

The properties of fibers and pulp have a significant impact on paper properties, and its properties for different uses was different. Tensile index and tear index are two important indicators of physical properties of paper, and they depend on the fiber strength, fiber binding force and the fiber length (Zhang and Xia, 2014; Seth, 1990; Paavilainen, 1993). Fig. 7 and 8 show that the change trends of the tensile index and tear index of the handsheets made by the pulp samples refined by four combined refining plates. In the initial stage of refining, the fibers rapidly swelled and fibrillated and their binding force continuously enhanced, and the tensile index of the finished paper was significantly improved (Zhang and Xia, 2014; He, 2010). Especially for the Disc 2, the tensile index increased sharply, reaching $58.884 \mathrm{~N} \cdot \mathrm{m} / \mathrm{g}$ within 12 minutes of refining, while in the later stage of refining, the increase rate in the tensile index of the paper was significantly slowed because of the decrease in the average fiber length. Finally, after 20 minutes of refining, the tensile index of the formed paper made by pulp

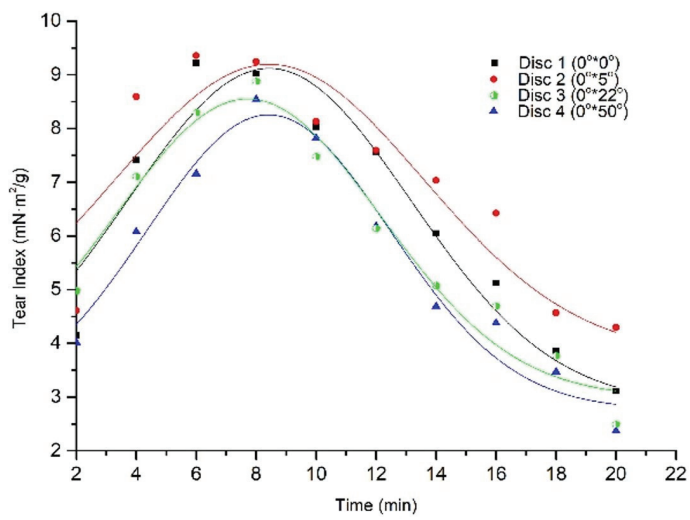

Fig. 8. Tear index change of paper formed by the four combined refining plates.

refined by Disc 1, Disc 2, Disc 3 and Disc 4 were $62.935 \mathrm{~N} \cdot \mathrm{m} / \mathrm{g}, 66.543 \mathrm{~N} \cdot \mathrm{m} / \mathrm{g}, 56.032 \mathrm{~N} \cdot \mathrm{m} / \mathrm{g}$ and 52.79 $\mathrm{N} \cdot \mathrm{m} / \mathrm{g}$ respectively. It can be seen from Fig. 7, the refining time to make a same tensile index of paper was shorter when it was made by pulp refined by the combined refining plate with a smaller bar angle.

The basic contradiction of refining was the opposition between the bonding force of fibers and the average fibers length (Zhang and Xia, 2014). The beating degree of the pulp is continuously improved during refining, and the fiber bonding force continues to increase, which is conducive to the improvement of paper strength. The tear index of the handsheets made by pulp refined by Disc 1, Disc 2, Disc 3 and Disc 4 increased rapidly to a maximum value of 9.212 $\mathrm{mN} \cdot \mathrm{m}^{2} / \mathrm{g}, 9.356 \mathrm{mN} \cdot \mathrm{m}^{2} / \mathrm{g}, 8.775 \mathrm{mN} \cdot \mathrm{m}^{2} / \mathrm{g}$ and 8.394 $\mathrm{mN} \cdot \mathrm{m}^{2} / \mathrm{g}$, after about 6 to 8 minutes of refining, as shown Fig. 8. As the increasing of refining time, the beating degree of the pulp increased continuously, while the average length of the fibers became shorter and shorter. Under the influence of the fiber bonding force and the fiber average length, the tear index of paper obtained from the four combined refining plates decreased after the point of maximum value, which indirectly indicated that excessively fiber cutting will 
decrease the tear strength of the paper. However, the downward trend of tear index of the resulting paper made by the pulp refined by different plates was quite different. From the above analysis, it can be known that the combined refining plates with a smaller bar angle could make the paper obtain a larger tear index. However, excessive refining will also reduce the tear index of the paper.

The beating degree, fiber external fibrillation and fiber morphology of pulp samples refined by the four combined refining plates were significantly different, and the physical properties of the paper made by the different pulp samples differed greatly. Therefore, it can be concluded that there is a obvious effect of the combined refining plates with different bar angles on the pulp and paper properties. By analyzing the pulp quality and SEM image of formed paper obtained from different processes, as shown in Fig. 3, 4 and 5 , it was found that fiber external fibrillation of the pulp samples refined by the combined refining plate with a smaller bar angle was more obvious than that of a larger bar angle. Fiber external fibrillation ensured a greater fiber bonding force, thus leading to better physical properties of the formed paper.

\section{CONCLUSION}

1. When the mixed pulp composed of unbleached softwood and bleached hardwood pulp was refined, the change of beating degree of pulp was greatly influenced by the bar angle of the combined refining plates. And the combined refining plates with smaller bar angles increased the beating degree of pulp faster and more significantly.

2. Under the condition of constant bar angle of the rotor, the smaller bar angles of the stator was, the faster fiber cutting was. And the fiber external fibrillation of pulp samples refined by the combined refining plate with smaller bar angle was more obvious compared to others. And the exposed thin thread-like and lamellar fibrils not only improved the interweaving ability between fibers, but also increased the fiber external specific surface area, which induces a higher strength and tightness of formed paper.

3. Combined refining plates with smaller bar angle showed a better ability to improve paper physical properties. When the pulp was over refined, the fiber was over shorted, therefore the fiber bonding force would be changed. And the increase rate of the tensile index of the paper obtained by the refining plates with a smaller bar angle was slowed down.

\section{ACKNOWLEDGMENT}

The authors sincerely thank the funding by the National Natural Science Foundation (Grant No. 507 45048) and Shaanxi Provincial key research and development Project (Fund) (Grant No. 2020 GY-105). The authors give a special thanks to Henan Cigarette Industry Sheet Co., Ltd. and Nantong Huayan Casting Co., Ltd.

\section{REFERENCES}

Brecht, W., Athanassoulas, M., Siewert, W.H. 1965. The influence of the setting angle between the tackle bars on the performance of beaters and refiners. Das Papier 19: 93-96.

Chauhan, V.S., Kumar, N., Kumar, M. 2011. Effect of separate and mixed refining of hardwood and softwood pulps on paper properties. Journal of Korea TAPPI 43(4): 1-10.

Chi, L.X., Liu, W.Y., Zang, B.Q. 2015. Improvement and optimization of the disc using for low consistency refining. China Pulp \& Paper 34(11): 42-44. 
Effect of Combined Refining Plates with Different Bar Angles on Paper Properties during Mixed Pulp Refining

Clark, J.D.A. 1969. Fibrillation, free water and fiber bonding. Tappi Journal 52(2): 335-340.

Elahimehr, A. 2014. Low consistency refining of mechanical pulp: the relationship between plate pattern, operational variables and pulp properties. Ph.D. Thesis, University of British Columbia, Canada.

Fernando, D., Gorski, D., Daniel, G. 2014. Exploring mechanisms of fiber development during $\mathrm{HC}$-and LC refining of mechanical pulps that govern pulp and paper properties. Helsinki, Finland, International mechanical pulping conference (IMPC 2014), pp. 1-7.

Guo, X.Y., Dong, J.X., Liu, H., Jiang, X.J., Luo, C. 2019. Application of Quality Function Deployment (QFD) in Disc Refiner Segment Design. China Pulp \& Paper 38(12): 44-49.

Hammar, L.A., Salmen, R., Sandberg, R. 2010. The effect of process conditions on pulp quality development in low consistency refining of mechanical pulp-TMP. Appita Journal 63(5): 377-380.

He, B. 2010. Refining, in papermaking principle and engineering, China Light Industry Press, Beijing, China.

ISO 5267-1:1999. 1999. Pulps - Determination of drainability - Part 1: Schopper-Riegler method. International Organization for Standardization, Geneva.

ISO 5269-1:2005. 2005. Pulps - Preparation of laboratory sheets for physical testing - Part 1: Conventional sheet-former method. International Organization for Standardization, Geneva.

Jayme, G., Hunger, G. 1957. The fiber-to-fiber bonding in paper handsheets seen by means of electronmicrographs. Das Papier 11: 140-145.

Kang, T. 2007. Role of external fibrillation in pulp and paper properties. Ph.D. Thesis, Helsinki University of Technology, Helsinki, Finland.

Kasmani, J.E., Nazeri, A.M., Samariha, A. 2013. The effect of fiber external fibrillation on paper properties. Iranian Journal of Wood and Paper Science Research 28(1): 1-10.

Li, W.P. 2002. Bar shape optimization of high consistency disc refiner. Hunan Papermaking (4): 9-10.

Liu, H., Dong, J.X., Guo, X.Y., Luo, C., Tian, X.H., Jiang, X.J., Wang, S., Yang, R.F., Duan, C.W., Wang, B., Qi, K. 2019. Study on Fiber Cutting Performance of Isometric Straight Bar Plate with Different Bar Angle. Journal of Korea TAPPI 51(5): 16-26.

Liu, Z. 2008. Introduction to pulping and papermaking. China light industry press, Beijing, China.

Paavilainen, L. 1993. Importance of cross-dimensional fiber properties and coarseness for the characterization of softwood sulphate pulp. Paperi ja Puu (Paper and Timber) 75(5): 343-351.

Peng, J., Liu, H. 2014. The main factors affecting bulk of paper and board. China Pulp \& Paper 33(6): 64-69.

Pfaffli, M. 2015. Rethinking the art of refining: Improving the efficiency and quality of refining. Beijing, China, International Mechanical Pulping Conference (CIPTE 2015), pp. 227-234.

Roux, J.-C., Bloch, J-F., Nortier, P. 2009. The net normal force per crossing point: a unified concept for the low consistency refining of pulp suspensions. Oxford, UK, $14^{\text {th }}$ Fundamental Research Symposium, pp. 51-67.

Seth, R.S. 1990. Fiber quality factors in papermaking - I The importance of fibre length and strength, Proceedings Material Research Symposium Vol. 197, Ed. by Caulfield, D.F., Passaretti, D. and Sobczynski, S.F., Cambridge University Press, England, UK.

Siewert, W., Selder, H. 1980. Economic use of energy in pulp refining. Appleton, USA, International Symposium on Fundamental Concepts of Refining, pp. 206-216. 
Shi, S.L., He, F.W. 2008. Pulp and paper analysis and testing. China light industry press, Beijing, China.

Strachan, J. 1938. Some physical aspects of beating, Proceedings of the Technical Section. Ph.D. Thesis, Manchester, U.K.

TAPPI T220 sp-01. 2001. Physical testing of pulp handsheets. TAPPI Press, Atlanta, GA.

Vomhoff, H. 1990. The influence of the bar angle on the refining process in a disc refiner. Technical Report, Institute for Paper fabrikation at the Technische Hochschule Darmstadt.
Wu, M. R., Lanouette, R., Valade, J. L. 2004. Understanding the fiber development during co-refining of white birch and black spruce mixtures. Part 1.Chemithermomechanical pulping. Pulp \& Paper Canada 105(12): 83-87.

Yang, J.S., Jiang, X.J. 2010. Refining energy saving by optimizing the plate of refiner. China Pulp \& Paper 29(10): 77-78.

Zhang, M.Y., Xia, X.X. 2014. Papermaking technology. China light industry press, Beijing, China. 